\title{
The Personalities of Twins: Just Ordinary Folks
}

\author{
Wendy Johnson, Robert F. Krueger, Thomas J. Bouchard, Jr., and Matt McGue \\ University of Minnesota, Twin Cities
}

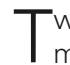

win studies have demonstrated that personality traits show moderate genetic influence. The conclusions drawn from twin studies rely on the assumptions that twins are representative of the population at large and that monozygotic and dizygotic twins are comparable in every way that might have bearing on the traits being studied. To evaluate these assumptions, we used Multidimensional Personality Questionnaire (MPQ) data from three samples drawn from the Minnesota Twin Registry (totaling 12,971 respondents) to examine the effect sizes associated with mean differences on the $11 \mathrm{MPO}$ scales and 3 higher-order MPQ factors for singletons versus twins and $M Z$ twins versus $D Z$ twins. The singletons in the samples were family members of the participating twins. We also used ratios of scale variances to examine the significance of variance differences. The only mean or variance difference replicated across all three samples was greater Social Closeness (about .1 standard deviation) for twins than for singletons. This difference was obtained for both males and females. It would appear that, with respect to personality, twins are not systematically different from other people. Our results also highlight the importance of replication in psychological research because each of our large samples showed differences not replicated in other samples.

Almost three decades ago Loehlin and Nicholls (1976) published a landmark study concluding that nearly all personality traits show moderate genetic influence. This conclusion was based on the observation that the pairwise correlations between monozygotic (MZ) twins were consistently greater than those between dizygotic (DZ) twins for various traits in a sample of nearly 800 pairs of adolescent twins. Since then, this observation has been replicated extensively using twin samples from many different populations, cultures, and age ranges, reared both together and apart, and a wide variety of personality measures reflecting both self-report and peer ratings (Bouchard \& Loehlin, in press; Caspi, 1998; Goldsmith, 1983; Loehlin, 1992; Riemann et al., 1997; Tellegen et al., 1988).

It is necessary to make several assumptions in order to conclude that the observation of higher correlations between MZ than between $\mathrm{DZ}$ twins implies that personality is genetically influenced in the population at large. One of these assumptions is that twins and their personalities are representative of that at-large population. A related assumption is that there are no systematic differences in personality between MZ and DZ twins. In spite of the importance of these assumptions for twin research, their validity has not been studied directly.
There are some well-established differences between singletons and twins. Twin births are more subject to obstetric complications such as premature birth, low birth weight, congenital malformations, perinatal mortality, and cerebral palsy (Bryan, 1993; Cunningham et al., 1989; Hall \& Lopez-Rangel, 1996; Hall, 1996; Naeye et al., 1978; Russell, 1961; Segal, 1999), though there is some evidence that improving medical technology has reduced the effects of these complications in recent years (Orlebeke et al., 1996). Twins are also more likely to be left-handed (Orlebeke et al., 1996), to experience delayed or difficult language development (Rutter et al., 1993) and to suffer reading problems, which may be related to an increase in the incidence of Attention Deficit Hyperactivity Disorder among twins (Levy et al., 1996). They may experience differences in rearing patterns and social and emotional experiences due to their interaction with each other and their presence as a paired set in other social groupings (Rutter \& Redshaw, 1991). There is evidence that, on average, twins have slightly lower IQs than singletons (Record et al., 1970), possibly resulting from birth complications, though this is not found in all studies (Nilsen et al., 1984; Posthuma et al., 2000) and may be changing due to improving medical technology.

On the other hand, studies examining rates of psychopathology among twins and singletons have generally concluded that twins are typical of the population at large. This is true for questionnaire reports of maladjustment and psychopathology among children and adolescents (Rutter \& Redshaw, 1991), maternal reports of problem behaviors in 2 to 3-year-old children (Oord et al., 1995), and selfreports of depression and anxiety among adults (Kendler et al., 1995). It is also true for more severe disorders seen in hospital settings such as schizophrenia, bipolar depression, and functional psychoses (Chitkara et al., 1988; Kringlen, 1967; Rosenthal, 1960), and for disease-related physical and lifestyle characteristics in adult women (Andrew et al., 2001). The question of the representativeness of twin personality scores in the normal range using large samples drawn from the population at large has not been addressed to our knowledge.

Address for correspondence: Wendy Johnson, University of Minnesota, Twin Cities, 14811 Stone Road, Minnetonka, MN 55391, USA.Email: john4350@tc.umn.edu 
Differences between $M Z$ and DZ twins have been studied even less systematically. Again, differences surrounding the circumstances of birth are the most clearly understood. DZ twins always have separate placentae (though they can occasionally fuse), which means that they also have separate chorions and amnions, the two protective fetal membranes that surround the fetus inside the placenta. In contrast, MZ twins may share the fetal membranes at the amniotic, chorionic, or placental levels. When the inner birth membranes are shared, structural abnormalities and shared fetal circulation are more common (Bryan, 1992; Machin, 2001; Martin et al., 1997), which may lead to differences in personality though there is also some evidence that personality may be more similar when chorions are shared (Sokol, 1995). Recent work comparing the IQs of monochorionic and dichorionic MZ twins drawn from a large systematic registry suggests little to no influence of chorion type on full-scale IQ, nor on most subtests of the Weschler Intelligence Scale for Children - Revised (Jacobs et al., 2001). This, however, says nothing about the ranges of personality observed among MZ and DZ twins. For psychopathology, Kendler et al. (1996) observed no differences in rates of first admission to the Swedish Psychiatric Registry over a 5-year period between MZ and same-sex $\mathrm{DZ}$ and between same-sex DZ and opposite-sex DZ twins in a Swedish birth cohort spanning 73 years. Prior, more limited studies had produced mixed results, with some showing lower and others showing higher rates of disorder in MZ twins (Fisher, 1973; Kringlen, 1967; Tienari, 1963).

The purpose of this study was to examine whether the means and variances of scores on a well-regarded personality self-report instrument (the Multidimensional Personality Questionnaire (MPQ), (Krueger et al., 2000; Patrick et al., in press; Tellegen, 1982; Tellegen, 1985) differ systematically between twins and their singleton family members and between $\mathrm{MZ}$ and $\mathrm{DZ}$ twins. We made use of three independent samples in which the participants completed slightly different versions of the MPQ. The results from the samples thus serve as constructive replications (Lykken, 1968) for each other.

\section{Materials and Method \\ Sample}

The personality data used in this study were provided by mail by participants in the Minnesota Twin Registry (MTR). The twin participants who form the foundation of the MTR were ascertained from birth records provided by the Minnesota State Health Department, and comprised about $80 \%$ of the approximately 10,400 surviving intact pairs born in Minnesota from 1936 through 1955 (about 8,400 pairs in all) (Lykken, 1968). In addition, their spouses, siblings, offspring, and parents were recruited. The initial mailing consisted of a biographical questionnaire that included five questions about twin similarity. We used these questions to determine the zygosity (MZ versus DZ) of the twins. This method of zygosity determination is highly accurate, achieving greater than 95\% accuracy when compared to serological analysis of blood samples (Lykken et al., 1990). The establishment and representativeness of the Registry are described in detail by Lykken et al. (1990).
In total, 12,971 twins and their singleton spouses and other family members completed the MPQ as part of the MTR. Participants in different recruitment waves received somewhat different versions of the MPQ. Specifically, 6,349 people completed a 300 -item version with dichotomous (true/false) response options, 4,666 people completed a shortened 198-item version with 4-point (definitely true, probably true, probably false, definitely false) response options, and 1,956 people completed a 300-item, 4response option form. We made use of this variation to construct 3 quasi-independent samples in which to assess twin versus singleton differences and $M Z$ versus $D Z$ differences so that we could assess the extent to which any differences we observed would be replicated across samples. The breakdown of the three samples by sex, twin status, and zygosity of twins is shown in Table 1 . To avoid confounds associated with sex-related personality differences, members of opposite-sex twin pairs were excluded from the $\mathrm{MZ}$ versus $\mathrm{DZ}$ comparisons, but they were included in the singleton versus twin comparisons. In situations where only one member of a twin pair completed the MPQ, that person was classified as a twin.

\section{Personality Measurement (the MPO)}

The MPQ is a factor analytically developed self-report personality inventory that measures 11 primary personality traits and 3 higher-order factors (Krueger, 2000; Tellegen \& Waller, 2001). The MPQ was designed to achieve relatively independent primary scales; thus no questions add to the scoring of more than one primary scale, and the superfactors do not simply reflect particular primary scales. The higher-order superfactors describe basic parameters of emotional and behavioral regulation. Positive Emotionality is primarily associated with the MPQ Wellbeing, Social Potency, Achievement, and Social Closeness scales. Negative Emotionality is most strongly associated with the

\section{Table 1}

Sample Sizes by Twin, Sex, and Zygosity Status for the 3 Multidimensional Personality Questionnaire Inventory Format Samples

\begin{tabular}{|c|c|c|c|}
\hline Status & $\begin{array}{l}\text { MPQ form } \\
300,2\end{array}$ & $\begin{array}{c}\text { MPQ form } \\
198,4\end{array}$ & $\begin{array}{l}\text { MPQ form } \\
300,4\end{array}$ \\
\hline \multicolumn{4}{|l|}{ Twins } \\
\hline Males & 1,256 & 1,282 & 366 \\
\hline Females & 1,954 & 1,741 & 570 \\
\hline \multicolumn{4}{|l|}{ Singletons } \\
\hline Males & 1,577 & 867 & 510 \\
\hline Females & 1,562 & 776 & 510 \\
\hline \multicolumn{4}{|l|}{ MZ twins } \\
\hline Males & 564 & 445 & 117 \\
\hline Females & 920 & 591 & 195 \\
\hline \multicolumn{4}{|c|}{ Same sex DZ twins } \\
\hline Males & 528 & 405 & 113 \\
\hline Females & 836 & 602 & 196 \\
\hline \multicolumn{4}{|c|}{$\begin{array}{l}\text { Notes:MZ = monozygotic; } \mathrm{DZ} \text { = same sex dizygotic. MPQ forms: number of items, } \\
\text { number of options per item. } \mathrm{MZ} \text { and } \mathrm{DZ} \text { twins are included in the overall group } \\
\text { of twins. Opposite sex dizygotic twins are included in the overall group of twins, } \\
\text { but not in the group of same sex } \mathrm{DZ} \text { twins. Members of broken twin pairs are } \\
\text { included in both the overall group of twins and in the appropriate MZ or DZ } \\
\text { group. See text for further explanation. }\end{array}$} \\
\hline
\end{tabular}


MPQ Stress-Reaction, Alienation, and Aggression scales. Constraint is primarily associated with the MPQ Control, Harm Avoidance, and Traditionalism scales.

\section{Analytic Procedures}

Because the existence of age and sex effects for the personality measures could affect the sample means in each group, the raw MPQ scores were adjusted for age and sex effects within each MPQ form sample. This was done by estimating the coefficients in the regression of MPQ scale score on age and age-squared separately for males and females, and using these coefficients to define the age-sex adjusted scores. The regression procedures are described more fully in McGue and Bouchard (1984).

In order to examine differences in mean trait levels, we calculated the effect size of each mean difference between twins and singletons and between MZs and DZs, using the age-corrected MPQ scores for each of the 11 primary scales and 3 higher-order factors. We did this separately for males and females within each MPQ form sample. To examine differences in variability of trait levels, we calculated ratios of the variances of MPQ scores in the same manner.

Given the large size of our samples, even small differences can be expected to be statistically significant. Consequently, we elected to focus on the magnitude of differences rather than their statistical significance. We decided to regard an effect size of .1 (or -.1) as noteworthy, but only if the effect size was at that level or higher in all three of our MPQ form samples. Cohen (1988) specifies an effect size of .2 as small; thus, the effect sizes with absolute value less than .1 that we disregarded can be considered extremely small. Similarly, for the ratios of variances, we decided to consider a variance ratio to be noteworthy only if it was greater than 1.2 or less than .83 (i.e. the reciprocal of 1.2) in all three of the MPQ form samples. Cohen based his definitions of small, medium, and large effect sizes on the proportions of the distributions that do not overlap for various effect sizes. Using this standard, a variance ratio of 1.2 is basically equivalent to an effect size of 1 .

\section{Results}

The results of our analysis of mean differences between twins and singletons are shown in Table 2. Most of the effect sizes of differences for males were well below the cutoff we had set of .1, and the few that exceeded that level did not tend to replicate in all three samples. The only exception was Social Closeness, which was higher in male twins by about .1 standard deviation in the two larger samples, and by about .2 standard deviation in the smallest sample. Aggression was higher in male singletons in the two larger samples by about .1 and .2 standard deviations, but the difference was well below .1 standard deviation in the smallest sample. This led, however, to a sample-weighted average over all three samples that was .12 standard deviations lower in twins than in singletons. The results for females were strikingly similar. Again, Social Closeness was higher in females by about .1 standard deviation in all three samples, but few other differences exceeded .1 standard deviation and the few that did were not replicated in other samples. Other than for Social Closeness, there were no sample-weighted averages that differed by as much as .1 standard deviation. To address the possibility that the personalities of twins and singletons were so similar because the twins and singletons were all family members, we also looked at mean differences between twins and spouses. Note that, because males and females were analysed separately, in so doing twins

\section{Table 2}

Effect Sizes of Differences by MPO Scale for the 3 Test Format Samples and the Sample-Weighted Average

\begin{tabular}{|c|c|c|c|c|c|c|c|c|}
\hline \multirow{3}{*}{ MPO Scales and Factors } & \multicolumn{6}{|c|}{ TWINS VS. SINGLETONS } & \multirow{2}{*}{\multicolumn{2}{|c|}{$\begin{array}{c}\text { Sample-Weighted } \\
\text { Average }\end{array}$}} \\
\hline & \multicolumn{2}{|c|}{ MPQ form 300, 2} & \multicolumn{2}{|c|}{ MPQ form 198, 4} & \multicolumn{2}{|c|}{ MPQ form 300,4} & & \\
\hline & Males & Females & Males & Females & Males & Females & Males & Females \\
\hline Wellbeing & -.03 & -.02 & .02 & .12 & .06 & -.04 & .00 & .03 \\
\hline Social Potency & -.02 & -.01 & -.13 & .00 & -.04 & -.13 & -.07 & -.03 \\
\hline Achievement & .03 & .07 & -.07 & .09 & .16 & .03 & .01 & .07 \\
\hline Social Closeness & .09 & .10 & .10 & .09 & .20 & .10 & .11 & .10 \\
\hline Stress Reactivity & -.04 & -.06 & -.04 & -.07 & .03 & .06 & -.03 & -.04 \\
\hline Alienation & .01 & .01 & -.01 & .12 & -.04 & .05 & .00 & .06 \\
\hline Aggression & -.10 & -.04 & -.18 & -.07 & -.04 & .00 & -.12 & -.05 \\
\hline Control & -.01 & -.04 & .08 & -.05 & -.04 & .01 & .02 & -.04 \\
\hline Harm Avoidance & .01 & -.05 & .01 & -.04 & -.04 & -.04 & .00 & -.05 \\
\hline Traditionalism & .03 & -.06 & .07 & -.02 & -.02 & -.06 & .03 & -.05 \\
\hline Absorption & .00 & .00 & -.06 & .08 & .10 & .00 & -.01 & .03 \\
\hline Positive Emotionality & .00 & .02 & -.05 & .12 & .13 & -.04 & .00 & .04 \\
\hline Negative Emotionality & -.05 & -.05 & -.10 & .00 & -.03 & .03 & -.07 & -.02 \\
\hline Constraint & .04 & -.04 & .09 & .01 & .00 & .01 & .05 & -.01 \\
\hline
\end{tabular}

Notes:MP0 forms: number of items, number of options per item. Twins include members of opposite sex pairs. Effect size is (twin mean - singleton mean)/pooled standard deviation. 
Table 3

Effect Sizes of Differences by MPQ Scale for the 3 Test Format Samples and the Sample-Weighted Average

\begin{tabular}{|c|c|c|c|c|c|c|c|c|}
\hline \multirow{3}{*}{ MPO Scales and Factors } & \multicolumn{6}{|c|}{ MZ TWINS VS. DZ TWINS } & \multirow{2}{*}{\multicolumn{2}{|c|}{ Sample-Weighted Average }} \\
\hline & \multicolumn{2}{|c|}{ MPQ form 300,2} & \multicolumn{2}{|c|}{ MPQ form 198, 4} & \multicolumn{2}{|c|}{ MPQ form 300, 4} & & \\
\hline & Males & Females & Males & Females & Males & Females & Males & Females \\
\hline Wellbeing & .06 & -.03 & .06 & .01 & .18 & .00 & .07 & -.01 \\
\hline Social Potency & .08 & .06 & .02 & -.03 & .27 & .08 & .08 & .03 \\
\hline Achievement & .15 & .03 & -.08 & .11 & .11 & .11 & .06 & .07 \\
\hline Social Closeness & .07 & .06 & .03 & .05 & .30 & .05 & .08 & .06 \\
\hline Stress Reactivity & -.02 & -.02 & -.06 & .05 & -.12 & -.11 & -.04 & .00 \\
\hline Alienation & -.20 & -.03 & -.04 & .07 & .04 & .00 & -.11 & .01 \\
\hline Aggression & .05 & -.05 & -.03 & .09 & -.13 & .01 & .00 & .01 \\
\hline Control & .09 & .03 & -.08 & .05 & -.17 & .02 & .00 & .04 \\
\hline Harm Avoidance & -.15 & .04 & -.03 & .04 & .03 & -.09 & -.09 & .02 \\
\hline Traditionalism & .06 & -.04 & -.03 & .12 & .13 & -.05 & .03 & .02 \\
\hline Absorption & -.01 & -.01 & .02 & .01 & .10 & .04 & .01 & .00 \\
\hline Positive Emotionality & .13 & .04 & .00 & .07 & .27 & .11 & .09 & .06 \\
\hline Negative Emotionality & -.08 & -.04 & -.07 & .09 & -.04 & -.04 & -.07 & .01 \\
\hline Constraint & -.01 & .01 & -.10 & .13 & .02 & -.04 & -.05 & .05 \\
\hline
\end{tabular}

Notes:MPQ forms: number of items, number of options per item. MZ = monozygotic; DZ = same sex dizygotic. Effect size is (MZ mean - DZ mean)/pooled standard deviation.

Table 4

Ratios of Variances by MPQ Scale for the 3 Test Format Samples and the Sample-Weighted Average

\begin{tabular}{|c|c|c|c|c|c|c|c|c|}
\hline \multicolumn{9}{|c|}{ TWINS VS. SINGLETONS } \\
\hline \multirow[t]{2}{*}{ MPO Scales and Factors } & \multicolumn{2}{|c|}{ MPQ form 300, 2} & \multicolumn{2}{|c|}{ MPQ form 198, 4} & \multicolumn{2}{|c|}{ MPQ form 300, 4} & \multicolumn{2}{|c|}{ Sample-Weighted Average } \\
\hline & Males & Females & Males & Females & Males & Females & Males & Females \\
\hline Wellbeing & 1.01 & 1.22 & 1.01 & 0.84 & 1.22 & 1.14 & 1.04 & 1.08 \\
\hline Social Potency & 1.08 & 1.04 & 0.98 & 0.93 & 1.03 & 1.00 & 1.04 & 1.00 \\
\hline Achievement & 0.83 & 0.93 & 1.11 & 0.83 & 0.93 & 0.96 & 0.95 & 0.90 \\
\hline Social Closeness & 1.04 & 1.04 & 0.98 & 0.88 & 0.91 & 0.90 & 1.00 & 0.96 \\
\hline Stress Reactivity & 1.03 & 1.04 & 1.05 & 1.00 & 1.00 & 0.94 & 1.03 & 1.01 \\
\hline Alienation & 1.05 & 0.97 & 1.15 & 1.41 & 0.87 & 1.03 & 1.06 & 1.13 \\
\hline Aggression & 0.90 & 0.90 & 0.94 & 0.92 & 0.98 & 0.99 & 0.92 & 0.92 \\
\hline Control & 1.08 & 1.06 & 0.92 & 0.98 & 0.92 & 1.06 & 0.99 & 1.03 \\
\hline Harm Avoidance & 1.01 & 1.04 & 0.92 & 0.98 & 1.14 & 0.94 & 0.99 & 1.00 \\
\hline Traditionalism & 1.05 & 1.20 & 1.02 & 0.98 & 0.93 & 1.21 & 1.02 & 1.12 \\
\hline Absorption & 1.08 & 1.05 & 1.06 & 1.02 & 0.99 & 0.84 & 1.06 & 1.01 \\
\hline Positive Emotionality & 1.07 & 1.06 & 1.11 & 0.81 & 1.12 & 1.03 & 1.09 & 0.96 \\
\hline Negative Emotionality & 1.03 & 1.02 & 1.17 & 1.14 & 0.84 & 0.92 & 1.05 & 1.05 \\
\hline Constraint & 1.03 & 1.14 & 0.88 & 1.08 & 0.99 & 1.09 & 0.97 & 1.11 \\
\hline
\end{tabular}

Notes:MPQ forms: number of items, number of options per item. Twins include members of opposite sex pairs. Ratio of variance is twin variance/singleton variance.

were never compared with their own spouses. The results were nearly identical, and can be obtained from Wendy Johnson upon request.

The results of our analysis of mean differences between MZs and DZs are shown in Table 3. For males, most of the effect size differences were well below .1 and no differences that exceeded that level were replicated in all three samples. Positive Emotionality was higher in MZs in two samples (by .1 and .3 standard deviations), but the difference was effectively 0 in the third sample. The sample-weighted average for Alienation was .11 standard deviation lower in
MZs than in DZs. The results for females were similar. Here, the only difference exceeding .1 standard deviation that was replicated even once was for Achievement (.1 standard deviation, with MZs higher, in two samples, but similar to DZs in the third sample). There were no sampleweighted averages that differed by as much as .1 standard deviation.

In general, the sample that completed the MPQ form with 300 items and 4 response options showed the greatest effect size differences. This sample was also the smallest, 
Table 5

Ratios of Variances by MPQ Scale for the 3 Test Format Samples and the Sample-Weighted Average

\begin{tabular}{|c|c|c|c|c|c|c|c|c|}
\hline \multirow{3}{*}{ MPQ Scales and Factors } & \multicolumn{6}{|c|}{ MZ TWINS VS. DZ TWINS } & \multirow{2}{*}{\multicolumn{2}{|c|}{ Sample-Weighted Average }} \\
\hline & \multicolumn{2}{|c|}{ MPQ form 300,2} & \multicolumn{2}{|c|}{ MPO form 198, 4} & \multicolumn{2}{|c|}{ MPQ 300, 4form } & & \\
\hline & Males & Females & Males & Females & Males & Females & Males & Females \\
\hline Wellbeing & 0.99 & 0.82 & 1.08 & 0.96 & 1.53 & 0.92 & 1.08 & 0.88 \\
\hline Social Potency & 0.91 & 0.92 & 0.87 & 0.95 & 1.22 & 1.06 & 0.93 & 0.95 \\
\hline Achievement & 1.06 & 0.97 & 0.83 & 1.08 & 1.42 & 1.27 & 1.01 & 1.04 \\
\hline Social Closeness & 0.97 & 0.98 & 1.02 & 1.03 & 1.63 & 0.94 & 1.06 & 0.99 \\
\hline Stress Reactivity & 0.91 & 1.02 & 1.02 & 0.95 & 1.24 & 1.02 & 0.99 & 1.00 \\
\hline Alienation & 1.35 & 1.07 & 1.22 & 1.09 & 0.90 & 1.19 & 1.25 & 1.09 \\
\hline Aggression & 0.99 & 1.17 & 0.97 & 0.88 & 1.69 & 0.88 & 1.06 & 1.03 \\
\hline Control & 1.01 & 0.91 & 1.00 & 1.10 & 0.98 & 1.33 & 1.00 & 1.03 \\
\hline Harm Avoidance & 0.91 & 0.94 & 0.95 & 0.97 & 1.09 & 0.94 & 0.94 & 0.95 \\
\hline Traditionalism & 0.89 & 0.89 & 1.11 & 0.90 & 1.21 & 0.96 & 1.01 & 0.90 \\
\hline Absorption & 1.01 & 0.99 & 0.96 & 0.88 & 1.16 & 1.00 & 1.01 & 0.95 \\
\hline Positive Emotionality & 1.02 & 0.87 & 0.91 & 1.01 & 1.57 & 0.89 & 1.03 & 0.92 \\
\hline Negative Emotionality & 1.11 & 1.11 & 1.06 & 1.00 & 0.93 & 1.16 & 1.07 & 1.07 \\
\hline Constraint & 0.93 & 0.87 & 0.95 & 0.99 & 1.00 & 1.06 & 0.94 & 0.94 \\
\hline
\end{tabular}

Notes:MPQ forms: number of items, number of options per item. $\mathrm{MZ}$ = monozygotic; $\mathrm{DZ}$ = same sex dizygotic. Ratio of variance is $\mathrm{MZ}$ variance/DZ variance.

being only about a third the size of the largest sample and less than half the size of the next largest.

Table 4 shows the ratios of variances for twins versus singletons. The situation was very similar to that for the mean differences: few of the variance ratios exceeded 1.2 (or, equivalently, were below .83), and those that did were not replicated across the other samples. The only situation where the variance ratio was greater than 1.2 in two samples was Traditionalism in females, but it was only .98 in the third sample.

Table 5 shows the ratios of variances for MZs versus DZs. Few ratios were greater than 1.2 or less than .83 , and those that were not replicated across the samples. In males, the only scale for which the ratio was greater than 1.2 in two samples was Alienation, with MZs showing greater variance in two samples, but less in the third. This led, again, to a sample-weighted average variance ratio of 1.25 for that scale. The situation for females was similar. There was no scale for which the ratio was greater than 1.2 even in two samples. There were also no sample-weighted average variances greater than 1.2 or less than .83 .

\section{$\overline{\text { Discussion }}$}

Despite large sample sizes, there was only one mean difference between twins and singletons that replicated across all three samples. That was the higher mean score for Social Closeness in twins, and it was apparent for both males and females. The effect size was only about .1, however, a difference generally considered trivial and which was not large enough to have an impact on Positive Emotionality, the higher-order factor to which Social Closeness primarily contributes. It is interesting to speculate, nonetheless, whether twins' greater Social Closeness extends to others around them or is primarily limited to the twin pair bond. Though the items in the Social Closeness scale include references to social relationships beyond the family, they also include several items that refer primarily to enjoyment of solitude (reverse-scored). In any event, the difference is unlikely to be of significance in behavioral genetic studies relying on the assumption that twins' personalities are representative of those in the population at large. There were no mean differences between MZs and DZs that replicated across all three samples. Similarly, there were no significant differences in variances that replicated across all three samples, either between singletons and twins or between MZs and DZs. There were sample-weighted averages that differed by about .1 standard deviation for Aggression between male twins and singletons and for Alienation between male MZs and DZs. These differences were not replicated across all three samples, and may be attributed to a lack of comparability of MPQ forms.

Taken together, these results suggest that it is reasonable to assume that twins are representative of the population at large for normal personality variation, and that MZs and DZs are comparable in this same way. In other words, with respect to personality, it is safe to say that twins are ordinary people who happen to come in matched sets.

That said, there were both significant mean differences and significant variance differences for some scales in some samples. In particular, the smallest sample (the 300-item, 4 response-option MPQ form) tended to show both the largest number of mean differences in excess of .1 standard deviation and the largest mean differences in absolute value. At 1,956 participants, this would not generally be considered to be a small sample. It is likely that these differences did not occur in the larger samples due to the law of large numbers, which states that the sample mean will approach the population mean as the sample size increases. The variation in results even in these large samples serves to 
emphasize the importance of replication in different samples in all psychological research.

\section{$\overline{\text { Acknowledgments }}$}

The development of the Minnesota Twin Registry was supported by Grant \#5 R01 MH37860 from the National Institute of Mental Health. Robert F. Krueger was supported by National Institute of Mental Health Grant R21 MH65137.

Address correspondence to Wendy Johnson or Robert F. Krueger at Department of Psychology, University of Minnesota, Elliott Hall, 75 East River Road, Minneapolis, MN 55455-0344.

\section{References}

Andrew, T., Hart, D. J., Snieder, H., Lange, M. D., Spector, T. D., \& MacGregor, A. J. (2001). Are twins and singletons comparable? A study of disease-related and lifestyle characteristics in adult women. Twin Research, 4(6), 464-477.

Bouchard, Jr. T. J., \& Loehlin, J. C. (in press). Genes, evolution, and personality. Behavior Genetics.

Bryan, E. M. (1992). Twins and higher multiple births: A Guide to their nature and nurture. London: Edward Arnold.

Bryan, E. M. (1993). Prenatal and perinatal influences on twin children: Implications for twin studies. In J. T. J. Bouchard, \& P. Popping (Eds.), Twins as a tool of behavioral genetics (pp. 218-25). Chichester, UK: John Wiley \& Sons, Ltd.

Caspi, A. (1998). Personality development across the life course. In W. Damon, \& N. Eisenberg (Eds.), Handbook of child psychology: Vol. 3; Social emotional, and personality development (311-388). New York: Wiley.

Chitkara, B., MacDonald, A., \& Reveley, A. M. (1988). Twin birth and adult psychiatric disorder: An examination of the case records of the Maudsley Hospital. British Journal of Psychiatry, 152, 391-398.

Cohen, J. (1988). Statistical power analysis (2nd ed.). Hillsdale, NJ: Erlbaum.

Cunningham, F. G., McDonald, P. C., \& Gant, N. F. (1989). Multifetal pregnancy. Williams Obstetrics (pp. 629-652). Norwalk, CT: Appleton \& Lange.

Fischer, M. (1973). Genetic and environmental factors in schizophrenia. Acta Psychiatrica Scaninavica Supplement, 238, 1-200.

Goldsmith, H. H. (1983). Genetic influences on personality from infancy to adulthood. Child Development, 54, 331-355.

Hall, J. G., \& Lopez-Rangel, E. (1996). Twins and twinning. In D. L. Rimoin, \& J. M. Connor, \& R. E. Pyeritz (Eds.), Principles and practice of medical genetics. New York: Churchill Livingstone.

Hall, J. G. (1996). Twins and twinning. American Journal of Medical Genetics, 61, 202-204.

Jacobs, N., Gestel, S. V., Devom, C., Thiery, E., Vernon, P., Devom, R., et al. (2001). Heritability estimates of intelligence in twins: Effects of chorion type. Behavior Genetics, 31, 209-217.

Kendler, K. S., Martin, N. G., Heath, A. C., \& Eaves, L. J. (1995). Self-report psychiatric symptoms in twins and their non-twin relatives: Are twins different? American Journal of Medical Genetics, 60, 588-591.

Kendler, K. S., Pedersen, N. L., Farahmand, B. Y., \& Persson, P. G. (1996). The treated incidence of psychotic and affective illness in twins compared with population expectation: A study in the Swedish Twin and Psychiatric Registries. Psychological Medicine, 26, 1135-1144.

Kringlen, E. (1967). Heredity and environment in the functional psychoses: Case histories. Oslo: Universitetsforlaget.

Krueger, R. F. (2000). Phenotypic, genetic, and nonshared environmental parallels in the structure of personality: A view from the Multidimensional Personality Questionnaire. Journal of Personality and Social Psychology, 79, 1057-1067.

Krueger, R. F., Caspi, A., \& Moffitt, T. (2000). Epidemiological personology: The unifying role of personality in populationbased research on problem behaviors. Journal of Personality, 68(6), 967-997.

Levy, F., McLaughlin, M., Wood, C., Hay, D., \& Waldman, I. (1996). Twin-sibling differences in parental reports of ADHD, speech, reading and behaviour problems. Journal of Child Psychology and Psychiatry, 37(5), 569-578.

Loehlin, J. C. (1992). Genes and environment in personality development. Newberry Park, CA: Sage.

Loehlin, J. C., \& Nichols, J. (1976). Heredity, environment and personality. Austin: University of Texas.

Lykken, D. T. (1968). Statistical significance in psychological research. Psychological Bulletin, 70, 151-159.

Lykken, D. T., Bouchard, Jr. T. J., McGue, M., \& Tellegen, A. (1990). The Minnesota Twin Family Registry: Some initial findings. Acta Genetica Medica et Gemellologiae, 39, 35-70.

Machin, G. (2001). Placentation in multiple births. Twin Research, 4, 150-155.

Martin, N., Boomsma, D. I., \& Machin, G. (1997). A twinpronged attack on complex traits. Nature Genetics, 17, 387-392.

McGue, M., \& Bouchard Jr. T. J. (1984). Adjustment of twin data for the effects of age and sex. Behavior Genetics, 14, 325-343.

Nilsen, S. T., Bergsjo, P., \& Nome, S. (1984). Male twins at birth and 18 years later. British Journal of Obstetrical Gynaecology, 91, 122-127.

Naeye, R. L., Tafari, N., Judge, D., \& Marboe, C. C. (1978). Twins: Causes of perinatal death in 12 United States cities and one African city. American Journal of Obstetrical Gynecology, 131, 267-272.

Oord, E. J. vd, Koot, H. M., Boomsma, D. I., \& Verhulst, F. C. (1995). A twin-singleton comparison of problem behavior in 2-3-year-olds. Journal of Child Psychology and Psychiatry and Allied Disciplines, 36(3), 449-458.

Orlebeke, J. F., Knol, D. L., Koopmans, J. R., Boomsma, D. I., \& Bleker, O. P. (1996). Left-handedness in twins: Genes or environment? Cortex, 32, 479-490.

Patrick, C., Curtin, J. J., \& Tellegen, A. (in press). Development and validation of a brief form of the Multidimensional Personality Questionnaire. Psychological Assessment.

Posthuma, D., DeGeus, E. J. C., Bleichredt, N., \& Boomsma, D. I. (2000). Twin-singleton differences in intelligence. Twin Research, 3, 83-87. 
Record, R. G., McKeown, T., \& Edwards, J. H. (1970). An investigation of the difference in measured intelligence between twins and single births. Annals of Human Genetics, 34, 11-20.

Riemann, R., Angleitner, A., \& Strelau, J. (1997). Genetic and environmental influences on personality: A study of twins reared together using the self- and peer-report NEO-FFI scales. Journal of Personality, 65, 449-476.

Rosenthal, D. (1960). Confusion of identity and the frequency of schizophrenia in twins. Archives of General Psychiatry, 3, 297-304.

Russell, E. (1961). Cerebral palsied twins. Archetypes of the Disabled Child, 36, 328-336.

Rutter, M., \& Redshaw, J. (1991). Growing up as a twin: Twinsingleton differences in psychological development. Journal of Child Psychology and Psychiatry and Allied Disciplines, 32(6), 885-895.

Rutter, M., Simonoff, E., \& Silberg, J. (1993). How informative are twin studies of child psychopathology? In T. J. Bouchard, Jr., \& P. Popping, (Eds.), Twins as a tool of behavioral genetics (pp. 179-194). Chichester, UK: John Wiley \& Sons, Ltd.

Segal, N. L. (1999). Entwined lives: Twins and what they tell us about human behavior. New York: Plume Books.
Sokol, D. K. (1995). Intrapair differences in personality and cognitive ability among young monozygotic twins distinguished by chorion type. Behavior Genetics, 25, 457-466.

Tellegen, A. (1982). Brief manual for the differential personality questionnaire. Minneapolis.

Tellegen, A. (1985). Structure of mood and personality and their relevance to assessing anxiety, with an emphasis on self-report. In A. H. Tuma, \& J. D. Maser (Eds.), Anxiety and the anxiety disorders (pp. 681-706). Hillsdale, NJ: Erlbaum.

Tellegen, A. T. J., Bouchard, J., Wilcox, K. J., Segal, N. L., Lykken, D. T., \& Rich, S. (1988). Personality similarity in twins reared apart and together. Journal of Personality and Social Psychology, 54(6), 1031-1039.

Tellegen, A., \& Waller, N. G. (2001). Exploring personality through test construction: Development of the Multidimensional Personality Questionnaire. In S. R. Briggs, J. M. Cheek (Eds.), Personality measures: Development and evaluation. Greenwich, CT: JAI Press.

Tienari, P. (1963). Psychiatric illnesses in identical twins. Acta Psychiatrica Scandinavica Supplement, 171. 